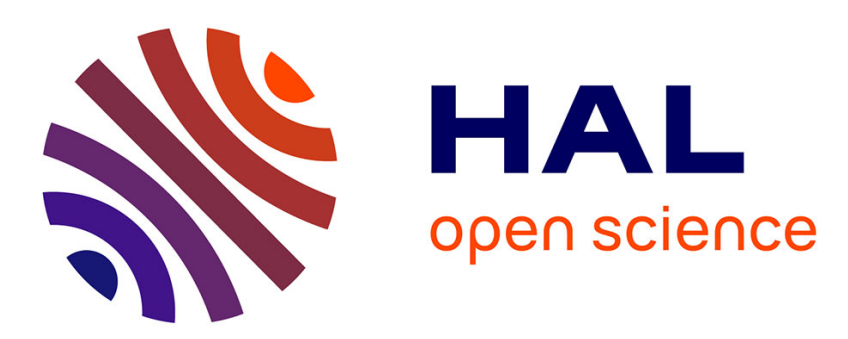

\title{
Avoidance bio-assays may help to test the ecological significance of soil pollution
}

Maite Martínez Aldaya, Christine Lors, Sandrine Salmon, Jean-François

Ponge

\section{- To cite this version:}

Maite Martínez Aldaya, Christine Lors, Sandrine Salmon, Jean-François Ponge. Avoidance bio-assays may help to test the ecological significance of soil pollution. Environmental Pollution, 2006, 140 (1), pp.173-180. 10.1016/j.envpol.2005.06.011 . hal-00363745

\section{HAL Id: hal-00363745 \\ https://hal.science/hal-00363745}

Submitted on 25 Feb 2009

HAL is a multi-disciplinary open access archive for the deposit and dissemination of scientific research documents, whether they are published or not. The documents may come from teaching and research institutions in France or abroad, or from public or private research centers.
L'archive ouverte pluridisciplinaire HAL, est destinée au dépôt et à la diffusion de documents scientifiques de niveau recherche, publiés ou non, émanant des établissements d'enseignement et de recherche français ou étrangers, des laboratoires publics ou privés. 
1 Avoidance bio-assays may help to test the ecological significance of soil 2 pollution

3

4 Maite Martínez Aldaya ${ }^{1}$, Christine Lors ${ }^{2}$, Sandrine Salmon ${ }^{3}$, Jean-François Ponge ${ }^{3}$

5

61 Universidad de Navarra, Facultad de Ciencias, Departamento de Zoologia y Ecologia, 731080 Pamplona, Spain

$8{ }^{2}$ Centre National de Recherche sur les Sites et Sols Pollués, 930 Boulevard Lahure, BP 537, 959505 Douai Cédex, France

$10{ }^{3}$ Museum National d'Histoire Naturelle, CNRS UMR 5176, 4 avenue du Petit-Chateau, 1191800 Brunoy, France

12

13 Corresponding author: J.F. Ponge, tel. +33160479213 , fax +33160465009 , e-mail: jean14 francois.ponge@wanadoo.fr

Capsule

Polluted soils are avoided by soil animals, a phenomenon which can be used as a cheap, sensitive tool for the early detection of environmental risk

Abstract

We measured the short-term (100') avoidance of a soil heavily polluted by

24 hydrocarbons by the soil springtail Folsomia candida, at six rates of dilution in a control, 25 unpolluted soil. We compared the results with those of long-term (40-day) population tests. 26 Five strains were compared, of varying geographical and ecological origin. When pure, the 27 polluted soil was lethal in the long-term and avoided in the short-term by all strains. 
1 Avoidance tests, but not population tests, were able to discriminate between strains.

2 Avoidance thresholds differed among strains. Two ecological consequences of the results

3 were discussed, i) toxic compounds may kill soil animals or deprive them from food, resulting

4 in death of populations, ii) pollution spots can be locally deprived of fauna because of escape

5 movements of soil animals. Advantages and limitations of the method have been listed,

6 together with proposals for their wider use in soil ecology and ecotoxicology.

7

Key-words: Avoidance; Ecotoxicological test; Folsomia candida; Soil pollution; Toxicity

9

\section{Introduction}

The repellence of toxic substances to soil animals has been known for a long time and was quantitatively assessed on several animal groups (Eijsackers, 1978; Hund-Rinke et al., 2003). The ecological assessment of soil toxicity is currently achieved through population and bioaccumulation bio-assays (Crouau et al., 2002). In standardized ecotoxicological tests using the earthworm Eisenia fetida (ISO 11268) and the springtail Folsomia candida (ISO 11267), populations of these soil animals are submitted to increasing doses of a toxicant, which they cannot escape during the duration of the bio-assay (one to three months). In nature, contrary to plants, most animals move to best places for feeding, reproduction and ecdysis, using chemical cues (Bengtsson et al., 1991; Salmon and Ponge, 2001). They are also able to escape deleterious environment or food using the same cues (Fábian and Petersen, 1994), except when they are immediately killed or immobilized by high doses of a toxicant (Best et al., 1978). Both attraction and repulsion are behavioural traits which increase the ecological fitness of sensitive species (Tranvik and Eijsackers, 1989). It has been demonstrated that most fungal strains and decomposition stages of leaf litter which were either attractive or repellent to soil springtails in the short-term were those which in the long-term favoured or disfavoured their growth, survival and reproduction, respectively (Sadaka-Laulan and Ponge, 2000). 
From a functional point of view, a sound basis for the early risk assessment of soil pollution at the ecosystem level should be to test whether a given soil will allow or not a community of soil organisms to colonize it (Filser and Hölscher, 1997), which lies on both dispersal to a habitat and population growth (Marinissen and Van den Bosch, 1992). It has been observed repeatedly that plant litter decomposition and building of a soil structure can be lost in polluted soils by the absence of key functional groups (Gillet and Ponge, 2002). Such functional losses may result not only from direct or indirect toxicity of a soil but also from the repellence of the same soil towards potential colonizers (Gillet and Ponge, 2004). Recently, several papers pointed on the need to combine ecototoxicological tests with avoidance tests for a proper assessment of soil toxicity (Heupel, 2002; Greenslade and Vaughan, 2003; da Luz et al., 2004).

The present study was aimed at comparing short-term avoidance tests with long-term tests of toxicity, using a soil polluted by polycyclic aromatic hydrocarbons (PAHs). Folsomia candida (Willem), a soil-dwelling springtail (Collembola: Isotomidae) currently used for the laboratory assessment of soil toxicity (Smit and Van Gestel, 1998), was considered representative of an invertebrate animal group which is widely distributed in the soil ecosystem and which plays a significant role in the regulation of microbial processes (Petersen and Luxton, 1982). Different strains of $F$. candida were compared, in order $(I)$ to check for strain variation, given the high degree of polymorphism which is known to occur in this cosmopolitan species (Goto and Ögel, 1961), (ii) to evaluate the sensitivity and validity of avoidance tests when performed on different clones of the same species (Chenon et al., 24 2000).

\section{Material and methods}


The test soil used in our experiments was obtained from a former coke oven site in northern France (Nord-Pas-de-Calais) in September 2003, then kept frozen at the laboratory. A control soil was collected in a nearby non-polluted, plant-restorated zone, within the same industrial site. Most physico-chemical properties of the test and the control soil are shown in

5 Tables 1 and 2. The moisture content was measured by gravimetry and the texture was 6 determined by laser particle size analysis. Soil $\mathrm{pH}_{\text {water }}$ was measured using a Consort $\circledast \mathrm{C} 83$ $7 \mathrm{pH}-$ meter fitted with glass electrodes corrected for temperature and a Schott@ box with 8 Ingold $\circledast$ combined electrodes. Total organic carbon was deduced from total carbon and 9 inorganic carbon values, which were determined with a TOC-5000A Shimatzu $®$ analyser. Total organic nitrogen was determined by the Kjeldahl method, and total phosphorus as well as metal concentrations ( $\mathrm{As}, \mathrm{Cd}, \mathrm{Co}, \mathrm{Cr}, \mathrm{Cu}, \mathrm{Ni}, \mathrm{Pb}$ and $\mathrm{Zn}$ ) were analysed by Inductive

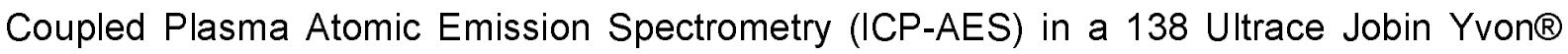
analyser after hot hydrofluoric and perchloric acid digestion of the solid phase. Concentrations of the 16 PAHs of the US EPA list of compounds (Greene et al., 1989) were measured using High Performance Liquid Chromatography in a 2690 HPLC Waters® analyser fitted with an ultraviolet inverted phase C 18 Supelcoß columm (length $250 \mathrm{~mm}$, internal diameter $2.1 \mathrm{~m}$ ), coupled to a 996 Waters ${ }^{\circledR}$ UV photodiode array detector, after extraction by dichloromethane/acetone $(50 / 50 \mathrm{v} / \mathrm{v})$ using the Accelerated Solvent Extracter Dionex® ASE 200. Chemical analyses were made in triplicate. concentration $(w / w)$, just before each experiment run, after thawing overnight at $3^{\circ} \mathrm{C}$. Deionized water was added in sufficient amount to obtain a paste for avoidance bio-assays or a solid substrate moistened at field capacity for population bio-assays. Rearing microcosms were checked weekly and deionized water was added to avoid desiccation. The use of a paste, instead of the natural soil, in avoidance experiments, was justified by the need to prevent animals from hiding in the soil when placed under constant illumination, and to achieve standard textural conditions of the substrate. 
Five F. candida strains collected in France were compared. In all cases, the clones came from a single thelytokous (parthenogenetic) female which was collected from a soil sample after extraction of microarthropods in a Berlese funnel, then sorted live. The animals were reared on fine quartz sand moistened with tap water and they were fed ad libitum with finely ground cow dung which was free of pesticides and antibiotics. Strain 1 was collected in October 2002 in a neutral soil slightly polluted by hydrocarbons (soil over tar deposit in an abandoned oil refinery) at Pechelbronn $\left(48^{\circ} 56^{\prime} \mathrm{N}, 7^{\circ} 50^{\prime} \mathrm{E}, \mathrm{pH}_{\text {water }} 6.7, \Sigma 16 \mathrm{PAHs} 6.0 \mathrm{mg} . \mathrm{kg}^{-}\right.$

$\left.{ }^{1}\right)$. Strain 2 was collected at the same date in a neutral, unpolluted control soil, $15 \mathrm{~m}$ from the previous site $\left(48^{\circ} 56^{\prime} \mathrm{N}, 7^{\circ} 50^{\prime} \mathrm{E}, \mathrm{pH}_{\text {water }} 7.0, \sum 16 \mathrm{PAHs} 0.9 \mathrm{mg} \cdot \mathrm{kg}^{-1}\right)$. Strain 3 was collected in May 2002 in an unpolluted neutral soil in the park of the laboratory (oak/hornbeam woodlot) at Brunoy $\left(48^{\circ} 40^{\prime} \mathrm{N}, 2^{\circ} 30^{\prime} \mathrm{E}, \mathrm{pH}_{\text {water }} 7.7, \Sigma 16 \mathrm{PAHs} 1.2 \mathrm{mg} \cdot \mathrm{kg}^{-1}\right)$. Strain 4 was collected in October 2002 in an unpolluted acid soil at Pfaffenbronn (oak/beech woodland), five kilometres from the Pechelbronn site $\left(48^{\circ} 59^{\prime} \mathrm{N}, 7^{\circ} 50^{\prime} \mathrm{E}, \mathrm{pH}_{\text {water }} 4.3\right.$, PAHs not determined). Strain 5 was collected in May 2002 in an acid soil (oak/pine woodland) at Brunoy $\left(48^{\circ} 40^{\prime} \mathrm{N}\right.$, $2^{\circ} 30^{\prime} \mathrm{E}, \mathrm{pH}_{\text {water }} 4.3, \mathrm{PAHs}$ not determined). Previous to each experimental run all specimens used had never been into contact with the polluted soil nor with any other kind of pollutant. Although the strains originated from very different sites, some of them were polluted, rearing conditions were standardized (quartz sand, moistened with tap water, with dry powdered cow dung added ad libitum), and the time between first inoculation by a female and experimental use of its offspring was such (at least a year) that we discarded any possible residual pollution in the rearing boxes. The test specimens were selected among fully developed (adult) animals of the same rearing box.

Avoidance experiments were performed in sterile polystyrene Petri dishes $(55 \mathrm{~mm}$ diameter, $10 \mathrm{~mm}$ height), the bottom of which was lined with two half-disks of filter paper made of glass fiber (50 mm diameter). The entire surface of each disk was then covered with a soil paste. One control half disk was covered with the control soil, the other with the test 
1 soil or a mixture of both soils. The two half-disks were separated by a $2 \mathrm{~mm}$ space line, at

2 the center of which one individual of $F$. candida was deposited. The position of the animal

3 was recorded each $20 \mathrm{~min}$ up to $100 \mathrm{~min}$. Previous assays showed that this duration was

4 enough although necessary to let the animal chose definitely between both sides after

5 preliminary exploration of the Petri dish. Twenty replicates, in two successive batches of ten,

6 were followed together. During the experiment, Petri dishes were placed under a Sharp $®$

7 fluorescent illuminator in a chamber at $20^{\circ} \mathrm{C}$. Blank experiments using control soil at both

8 sides checked for the absence of any light gradient effect which could bias the results

9 (Salmon and Ponge, 1998). Totals of five counts over $100 \mathrm{~min}$ for each Petri dish were used

10 for testing differences between control and polluted sides, using sign tests (Sokal and Rohlf,

11 1995). Notice that unit data, ranging from 0 to 5 , measured the average position of a single

12 individual (from nil to constant avoidance) during the duration of the experiment and thus

13 were not replicated over time. Replication and corresponding calculation of the degrees of

14 freedom concerned only the 20 petri dishes which were independently followed in the course

15 of time. Previous experiments with the same design showed that average values for choice position should be preferred to end-point values, given that choice by Collembola is rapid, often occurring within $10 \mathrm{~min}$, but erratic movements may still occur thereafter (Salmon and Ponge, 1998, 2001; Sadaka-Laulan and Ponge, 2000).

In the course of each avoidance experimental run, some animals were found dead or paralyzed, their number increasing with the concentration of the polluted soil in the dilution series. These animals were counted separately, then discarded from the data set used for the sign test.

Population response was assessed by introducing batches of ten adults into each of five rearing chambers (polystyrene boxes $45 \mathrm{~mm}$ diameter, $25 \mathrm{~mm}$ height), fifth-filled with the control soil or with the same mixtures of control/polluted soil as used for avoidance experiments. A small amount of dry cattle dung powder was added above the soil substrate, 
1 then boxes were incubated at $20^{\circ} \mathrm{C}$ in darkness during 40 days. At the end of the experiment,

2 the whole population (including the ten females introduced at the start of the experiment) was

3 collected. We used forceps for collecting animals which were visible over the substrate.

4 Animals living deep in the substrate were collected by flotation under excess water, and all

5 specimens were immediately counted. Population sizes were compared between control and

6 test soils using t tests (Sokal and Rohlf, 1995).

7

3. Results

9

The studied substrate exhibited a high content in PAH compounds but was not polluted by heavy metals, arsenic or cyanides (Tables 1 and 2).

12

Figure 1 shows the results of all avoidance tests which were performed on the five strains of $F$. candida. There was no bias due to a possible light gradient effect, showing that light was homogeneously distributed throughout the observation area. All blank tests, using the control soil on both sides of Petri dishes, did not reveal any significant departure from random values, nor any mortality during the test period. At a test soil concentration of $10 \%$ or higher, specimens from all strains avoided the test side. Strain 4 (acid soil Pfaffenbronn) did not avoid the test side to the same extent than the other four strains, even at the highest concentration (100\%), while avoidance was total for the other four strains. At $1 \%$ and $5 \%$ test soil, Strain 4 did not avoid the test side, while the other four strains did. At $0.35 \%$ test soil, avoidance was displayed by Strain 2 only. Thus the five strains could be classified in a decreasing order of sensitivity to the test soil: $2>1-3-5>4$. For all strains, the decrease from the point of minimum (or nil) avoidance to the point of maximum (or total) avoidance was progressive.

The number of animals which were observed to die or become motionless during avoidance runs increased according to the concentration of the test soil (Fig. 2). All animals 
1 were alive and actively moving when the test soil was diluted more than 20 times $(<5 \%)$.

2 However, Strain 4 began to be affected only at $10 \%$ test soil, contrary to the four other

3 strains, pointing again to a lower sensitivity of this strain.

4

5

6

Figure 3 shows the results of population tests. At 10,50 and $100 \%$ test soil, all introduced animals were killed, whatever the strain. At $5 \%$ test soil, some animals were still alive in some boxes at the end of the experimental period (40 days), but reproduction was rarely observed. Below 5\% test soil, reproduction occurred in all boxes, without any significant departure from the control soil. In the control soil the number of juveniles produced after 40 days was $119 \pm 30,109 \pm 17,39 \pm 5,116 \pm 30$ and $90 \pm 13$ (mean \pm S.E.) with Strains 1 to 5 , respectively. The reproduction rate and the coefficient of variation met the validity criterion of the ISO guideline (ISO 11267) except for Strain 3, which displayed a lower reproduction rate than all other strains (one-way ANOVA on log-transformed data followed by SNK procedure, $\mathrm{P}=2 \cdot 10^{-4}$ ). Contrary to avoidance tests, threshold concentrations did not differ between strains and the passage from the absence of effect to total or near total effect was abrupt whatever the strain.

\section{Discussion}

Toxicity of the test soil to the Collembolan Folsomia candida was clearly shown by population tests (Fig. 3). When the test soil was diluted to $5 \%$ in the control soil the batch of 10 adult animals did not reproduce (strains 1 and 3 ) or even partially or totally died (other strains). At higher concentration, mortality at 40 days was total. The PAH content of the test soil could explain this toxicity, however, we cannot discard the effect of other compounds, not dosed in the present study, such as tar. A visual inspection of the polluted soil under a dissecting microscope revealed an abundance of dark more or less spherical pellets $\leq 1 \mathrm{~mm}$ which, when broken with scissors, revealed a black, vitrified core part surrounded by a mixture of organic matter and clay particles. Such strongly heterogeneous material may 
1 explain the absence of a linear, or even curvilinear dose-response relationship when the

2 animals were let several weeks into contact with the test substrate. We hypothesize that 3 there was a threshold of dilution above which the animals were able to avoid a few, 4 dispersed toxic micro-sites and thus behaved like in an innocuous environment (Tranvik and

5 Eijsackers, 1989). Such micro-heterogeneity of the substrate did not occur in our avoidance 6 tests, probably because of the more intense mixing which resulted from the preparation of 7 the muddy paste.

Depite the fact that the test soil was clearly toxic to $F$. candida and the control soil was not, we cannot discard possible effects of soil type to explain why the animals preferred the control soil in avoidance experiments. The use of another, not polluted soil, coming from the same industrial site, was preferred to a neutral substrate such as quartz sand. To be realistic an avoidance experiment should mimic what the animals have to their disposal in the site from which the test soil was originating, i.e. a patchwork of polluted and unpolluted micro-sites, reflected in ou test and control soils, respectively.

Our results point at a good correlation between avoidance and toxicity tests. However, only avoidance tests discriminated between strains of $F$. candida. Genetic polymorphism has been demonstrated between clones of $F$. candida coming from several European laboratories but this could not be correlated with ecotoxicological responses to cadmium and phenanthrene (Chenon et al., 2000). In particular these authors showed that the lowest concentration affecting mortality and reproduction did not differ between strains, as in our study, but they did not perform avoidance experiments.

What is the ecological significance of pollution avoidance? In a study comparing two isotomid species coming from the Gusum area, a metal-contaminated site in Sweden, 27 Tranvik and Eijsackers (1989) observed that Folsomia fimatarioides was able to avoid diets and substrates highly polluted by heavy metals $(\mathrm{Cu}+\mathrm{Zn})$, while Isotomiella minor was not. 
1 The former species was more abundant than the latter when exposed to the highest

2 concentration of metals in the soil. The authors concluded that avoidance of polluted diets

3 and substrates offered an advantage to $F$. fimetarioides over $I$. minor in polluted soils,

4 because it allowed the former species to select less polluted micro-sites and food in a

5 heterogeneous environment. This indicates that even tiny animals, such as springtails, are

6 capable of perceiving differences in their habitat. At the scale of life of micro-arthropods, the

7 landscape is made of islands of food resources and habitats between which the animals

8 move and which they select for nutrition, moulting, and oviposition (Joosse, 1971). Shape

9 and colour are of no use within the soil where animals live in darkness, therefore they must

10 use chemical and mechanical sense organs for detecting deleterious and attractive habitat

11 and food. Species-specific aggregation in conditioned sites increases the probability to find

12 suitable places and favours mating (Joosse, 1971). Avoidance and attraction may be

13 directional and selective (Verhoef and Nagelkerke, 1977). Repellent substances may also act

14 by discouraging food intake (Fountain and Hopkin, 2001) or by favouring non-directional

15 dispersal (Sjögren, 1997), thus increasing the chance an animal will find a suitable place where it will remain motionless (Michelozzi et al., 1997). However, a high dose of pollutant or

a longer time of exposure may decrease mobility (Petersen and Gjelstrup, 1998). Some animals became motionless in the course of our short-term avoidance test (Fig. 2). Thus, when the toxicant exhibits paralyzing effects, escape movements may prevent the animals from intoxication but only at some distance from the poison source. This is a key point for assessing the ecological significance of avoidance, in particular in the case of PAH mixtures, which act as narcotics and thus may inhibit locomotory activity (Landrum et al., 2003).

Pollution may affect soil animal communities and their functioning in two ways. First, toxicity kills animals or prevents them from feeding and reproduction. This only occurs at the right place where the pollutant has been deposited. Indirect effects through collapses in microbial and plant communities (Gillet and Ponge, 2003) or predator populations 28 (Abrahamsen et al., 1980) are also spatially limited and fall in this category. Second, 
1 repellence of toxicants may help the animals to find refuges deeper in the soil or outside the pollution spot. In this case, the final result will depend on whether the animal is adapted to live in deeper soil or is able to move rapidly at the soil surface; thus it will depend on speciesspecific biological traits. Such spatial shifts have been described or they can be suspected from existing data. Gillet and Ponge (2003) observed that several surface-dwelling species of

6 Collembola, collected in an organic soil strongly polluted by heavy metals $(Z n+C d)$, visited the underlying clay-rich mineral soil, and fed on the mineral substrate rather than on the metal-contaminated organic layer. Vertical migration of Collembola down to the mineral soil was experimentally demonstrated by Best et al. (1978) following naphthalene application on the ground surface, but this phenomenon occurred only at the lowest rate of application. A decrease in horizontal migration was demonstrated at all rates of application. Thus the few existing data point to vertical migration of microarthropods to deeper soil layers rather than to outward horizontal migration. Consequences are that low rates of application of a pollutant, eventually not reaching toxic doses, may impoverish the topsoil in some animal species. This may result into functional shifts such as organic matter accumulation and proliferation of mycelial webs (Gillet and Ponge, 2002).

Whether avoidance tests should be preferred to mortality/repoduction tests for the risk assessment of soil pollution is prone to discussion. The laboratory assessment of repellence is cheaper (total duration of a test three to four hours, preparation and calculation included) and needs a much lesser amount of specimens than standardized ecotoxicological tests based on population response. Tests of a longer duration are even disqualified in the case of neurotoxic compounds, as mentioned above. From an ecological point of view, avoidance tests seem more relevant than classical ecotoxicological tests, and they are more sentitive to within-species populational differences. However, there are several limitations to a wider use of avoidance tests as an alternative to the direct assessment of toxicity. Some substances, such as cadmium salts, are not perceived as repellent, while they are toxic when the animals are forced to keep into contact with them (Greenslade and Vaughan, 2003). This means that 
1 this toxicant cannot be avoided in the environment and, thus, will destroy entire populations,

2 contrary to others which the animals currently escape. Sadaka et al. (1998) showed that a

3 basidiomycetous fungal strain was attractive to the collembolan Onychiurus sinensis in short-

4 term experiments while it affected negatively its growth, survival and reproduction in the long-

5 term. However, examples of compounds or substrates which are both repellent and good for

6 population growth are unknown.

7

The above examples show that a proper combination of avoidance and toxicity tests could be the best promising tool for the prediction of environmental effects of pollution. If avoidance occurs at the same or at a higher rate of application than toxicity, this means that pollution will definetely kill the populations of the test organism. If avoidance occurs at a lower rate of application than toxicity, as in our experiment, or if not any toxicity is detected while the pollutant or the substrate proves to be repellent, this means that pollution will deprive the site form the test organism even in the absence of toxic effects. Thus, avoidance can be used as a tool to detect environmental hazards other than toxicity.

Clearly, the proposed avoidance test, applying a toxic soil as an artifical paste at the bottom of a battery of Petri dishes is a compromise between the need for a rapid and easy assessment of soil toxicity, and the need to find more realistic and ecologically-relevant methods. Microscosms, filled with a natural test soil, allow avoidance to be studied at the community level (Chauvat and Ponge, 2002; Ponge et al., 2002; Gillet and Ponge, 2004; Garnier and Ponge, 2004), and they can be at first sight considered more realistic. However, it needs several weeks for the animals to select between test and control substrates in a confined environment which, in the case of neurotoxic, volatile compounds acting at distance, may imped any assessment of behavioural effects. In this case, we consider more realistic to test the immediate reaction of the animals in a semi-natural system purposely designed for that. 


\section{Acknowledgements}

The authors are indebted to the Agence de l'Environnement et la Maîtrise de

l'Énergie (ADEME) for financial support and to the Agence Française de Normalisation (AFNOR) for fruitful discussions about the ecological significance of avoidance tests. (1)

\section{References}

Abrahamsen, G., Hovland, J., Hågvar, S., 1980. Effects of artificial acid rain and liming on soil organisms and the decomposition of organic matter. In: Hutchinson, T.C., Havas, M. (Eds.), Effects of Acid Precipitation on Terrestrial Ecosystems. Plenum Press, New York, pp. 341-362.

Bengtsson, G., Hedlund, K., Rundgren, S., 1991. Selective odor perception in the soil Collembola, Onychiurus armatus. Journal of Chemical Ecology 17, 2113-2125.

Best, G.R., Nabholz, J.V., Ojasti, J., Crossley, D.A.Jr, 1978. Response of microarthropod populations to naphthalene in three contrasting habitats. Pedobiologia 18, 189-201.

Chauvat, M., Ponge, J.F., 2002. Colonization of heavy metal-polluted soils by Collembola: preliminary experiments in compartmented boxes. Applied Soil Ecology 21, 91-106.

Chenon, P., Rousset, A., Crouau, Y., 2000. Genetic polymorphism in nine clones of a parthenogenetic collembolan used in ecotoxicological testing. Applied Soil Ecology 14, 103-110.

Crouau, Y., Gisclard, C., Perotti, P., 2002. The use of Folsomia candida (Collembola, Isotomidae) in bioassays of waste. Applied Soil Ecology 19, 65-70. 
2 Eijsackers, H., 1978. Side effects of the herbicide 2,4,5-T affecting mobility and mortality of the springtail Onychiurus quadriocellatus Gisin (Collembola). Zeitschrift für Angewandte Entomologie 86, 349-372.

5

6

Fábian, M., Petersen, H., 1994. Short-term effects of the insecticide dimethoate on activity and spatial distribution of a soil inhabiting collembolan Folsomia fimetaria Linné (Collembola: Isotomidae). Pedobiologia 38, 289-302.

Filser, J., Hölscher, G., 1997. Experimental studies on the reactions of Collembola to copper contamination. Pedobiologia 41, 173-178.

Fountain, M.T., Hopkin, S.P., 2001. Continuous monitoring of Folsomia candida (Insecta: Collembola) in a metal exposure test. Ecotoxicology and Environmental Safety, Section

Garnier, S., Ponge, J.F., 2004. Acid-tolerant Collembola cannot colonize metal-polluted soils at neutral pH. Applied Soil Ecology 26, 201-208. B, Environmental Research 48, 275-286.

Gillet, S., Ponge, J.F., 2003. Changes in species assemblages and diets of Collembola along a gradient of metal pollution. Applied Soil Ecology 22, 127-138.

Gillet, S., Ponge, J.F., 2004. Are acid-tolerant Collembola able to colonise metal-polluted soil? Applied Soil Ecology 26, 219-231. 
1 Goto, H.E., Ögel, S., 1961. Variation in the mucro of Folsomia (Collembola: Isotomidae). The Entomologist 94, 105-107.

3

4 Greene, J.C., Bartels, C.L., Warren-Hicks, W.J., Parkhurst, B.R., Linder, G.L., Peterson, S.A., Miller, W.E., 1989. Protocols for Short-Term Toxicity Screening of Hazardous Waste Sites, EPA/600/3-88/029. United States Environmental Protection Agency, Corvallis, Oregon.

8

Greenslade, P., Vaughan, G.T., 2003. A comparison of Collembola species for toxicity testing of Australian soils. Pedobiologia 47, 171-179.

Heupel, K., 2002. Avoidance response of different collembolan species to Betanal. European Journal of Soil Biology 38, 273-276.

14

Hund-Rinke, K., Achazi, R., Römbke, J., Warnecke, D., 2003. Avoidance test with Eisenia fetida as indicator for the habitat function of soils: results of a laboratory comparison test. Journal of Soils and Sediments 3, 7-12.

ISO 11267, 1999. Soil Quality. Inhibition of Reproduction of Collembola (Folsomia candida). International Standards Organization, Geneva, Switzerland.

ISO 11268, 1994. Soil Quality. Effects of Pollutants on Earthworms (Eisenia fetida). International Standards Organization, Geneva, Switzerland.

Joosse, E.N.G., 1971. Ecological aspects of aggregation in Collembola. Revue d'Écologie et de Biologie du Sol 8, 91-97. 
1 Landrum, P.F., Lotufo, G.R., Gossiaux, D.C., Gedeon, M.L., Lee, J.H., 2003. Bioaccumulation and critical body residue of PAHs in the amphipod, Diporeia spp.: additional evidence to support toxicity additivity for PAH mixtures. Chemosphere 51,481 489.

5

6

da Luz, T.N., Ribeiro, R., Sousa, J.P., 2004. Avoidance tests with Collembola and earthworms as early screening tools for site-specific assessment of polluted soils. Environmental Toxicology and Chemistry 23, 2188-2193.

Marinissen, J.C.Y., Van den Bosch, F., 1992. Colonization of new habitats by earthworms. Oecologia 91, 371-376.

12

Michelozzi, M., Raschi, A., Tognetti, R., Tosi, L., 1997. Eco-ethological analysis of the interaction between isoprene and the behaviour of Collembola. Pedobiologia 41, 201-

Petersen, H., Gjelstrup, P., 1998. Effects of the insecticide dimethoate on the behaviour of Folsomia fimetaria (L.) (Collembola: Isotomidae). Applied Soil Ecology 9, 389-392.

Petersen, H., Luxton, M., 1982. A comparative analysis of soil fauna populations and their role in decomposition processes. Oikos $39,288-388$.

Ponge, J.F., Bandyopadhyaya, I., Marchetti, V., 2002. Interaction between humus form and herbicide toxicity to Collembola (Hexapoda). Applied Soil Ecology 20, 239-253.

Sadaka-Laulan, N., Ponge, J.F., 2000. Influence of holm oak decomposition stage on the biology of Onychiurus sinensis Stach (Collembola: Onychiuridae). European Journal of Soil Biology 36, 97-105. 
2 Sadaka-Laulan, N., Ponge, J.F., Roquebert, M.F., Bury, E., Boumezzough, A., 1998. Feeding preferences of the Collembolan Onychiurus sinensis for fungi colonizing holm oak litter (Quercu rotundifolia Lam.). European Journal of Soil Biology 34, 179-188.

Salmon, S., Ponge, J.F., 1998. Responses to light in a soil-dwelling springtail. European Journal of Soil Biology 34, 199-201.

8

Salmon, S., Ponge, J.F., 2001. Earthworm excreta attract soil springtails: laboratory experiments on Heteromurus nitidus (Collembola: Entomobryidae). Soil Biology and Biochemistry 33, 1959-1969.

12

Sjögren, M., 1997. Dispersal rates of Collembola in metal polluted soil. Pedobiologia 41, 506513.

Smit, C.E., Van Gestel, C.A.M., 1998. Effects of soil type, prepercolation, and ageing on bioaccumulation and toxicity of zinc for the springtail Folsomia candida. Environmental Toxicology and Chemistry $17,1132-1141$.

Sokal, R.R., Rohlf, F.J., 1995. Biometry, $3^{\text {rd }}$ ed. Freeman, New York, NY.

Tranvik, L., Eijsackers, H., 1989. On the advantage of Folsomia fimetarioides over Isotomiella minor (Collembola) in a metal polluted soil. Oecologia 80, 195-200.

Verhoef, H.A., Nagelkerke, C.J., 1977. Formation and ecological significance of aggregations in Collembola. An experimental study. Oecologia 31, 215-226. 
Table 1. Physical and chemical characteristics of the test soil and the corresponding control soil. Means of three replicated measures followed by standard deviations. Concentrations are expressed on a dry soil basis

\begin{tabular}{|c|c|c|c|c|c|c|c|}
\hline & Texture & $\mathrm{pH}_{\text {water }}$ & $\begin{array}{l}\text { Total organic } \\
\text { carbon (\%) }\end{array}$ & $\begin{array}{l}\text { Total organic } \\
\text { nitrogen } \\
\left.(\mathrm{mg.kg})^{-1}\right)\end{array}$ & $\begin{array}{l}\text { Total } \\
\text { phosphorus } \\
\text { (mg.kg })\end{array}$ & $\begin{array}{l}\Sigma 16 \text { PAHs } \\
\left(\mathrm{mg} . \mathrm{kg}^{-1}\right)\end{array}$ & $\begin{array}{l}\text { Cyanides } \\
\text { (mg.kg-1) }\end{array}$ \\
\hline Test soil & Silty sand & $7.9 \pm 0.02$ & 9 & 1700 & 620 & $2894 \pm 54$ & 0.8 \\
\hline Control soil & Medium silt & $8.4 \pm 0.04$ & 0.7 & 670 & 410 & $0.97 \pm 0.09$ & $<0.1$ \\
\hline
\end{tabular}


Table 2. Concentration of heavy metals $\left(\mathrm{mg}^{-\mathrm{kg}^{-1}}\right)$ in the test soil compared with geochemical background, i.e. concentrations measured over a wide range of unpolluted agricultural and forest soils (Sterkeman et al. 2002). Means of three replicate measures were followed by standard deviations. Concentrations are expressed on a dry soil basis

\begin{tabular}{llllllll}
\hline & As & Cd & Co & Cr & Cu & Ni & Pb \\
\hline Test soil & $6.5 \pm 0.5$ & $<0.4$ & $9.6 \pm 0.2$ & $32.9 \pm 0.3$ & $19.3 \pm 0.4$ & $19.8 \pm 0.2$ & $23.9 \pm 0.8$ \\
$\begin{array}{l}\text { Geochemical } \\
\text { background }\end{array}$ & $8.9 \pm 1.2$ & $0.4 \pm 0.03$ & $9.3 \pm 0.9$ & $48.8 \pm 2.7$ & $16.7 \pm 1.8$ & $24.7 \pm 5.7$ & $38.4 \pm 5.6$ \\
\hline
\end{tabular}




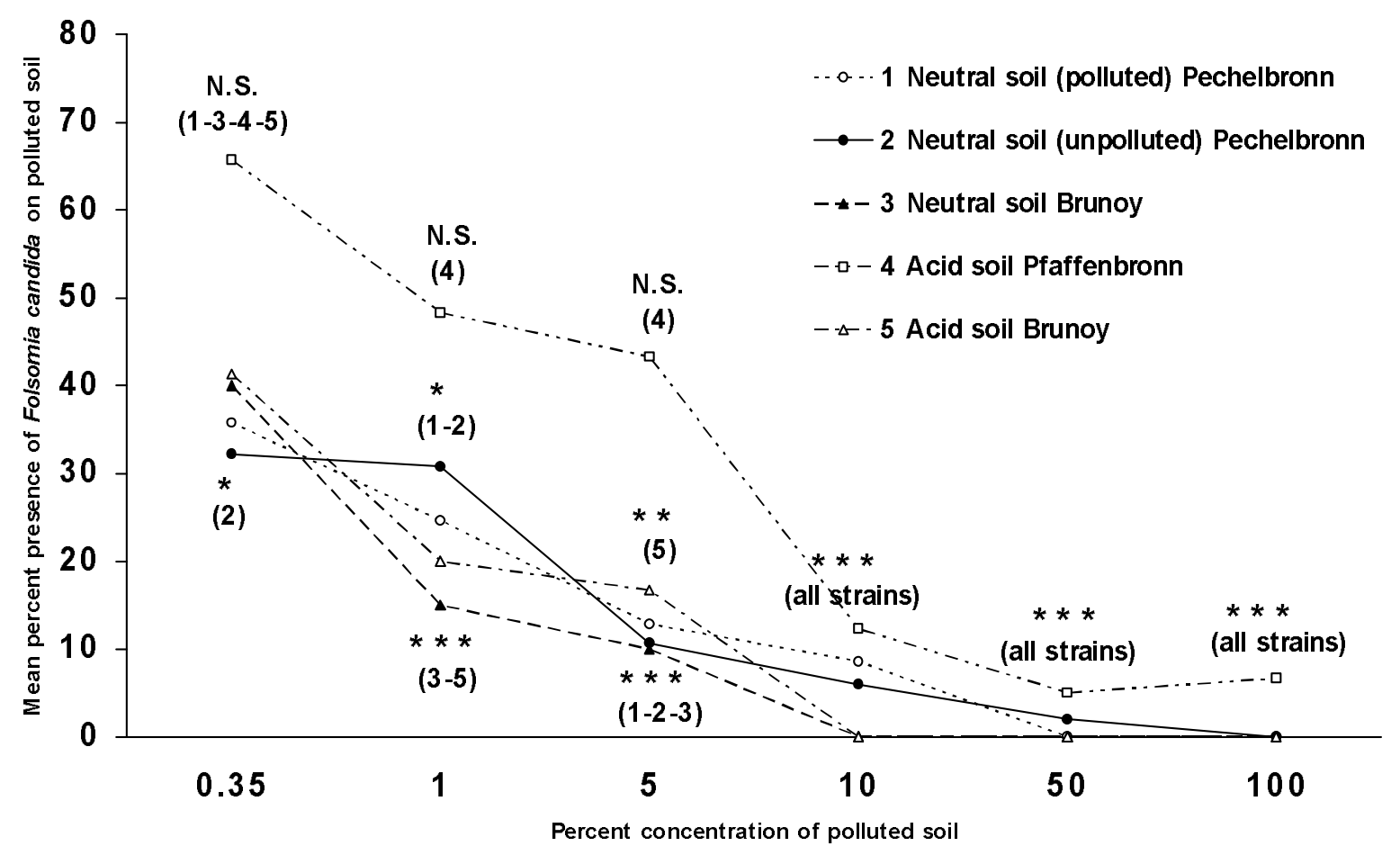

Fig. 1. Avoidance tests. Mean percent presence of five strains of Folsomia candida on polluted side of Petri dishes ( 5 counts at 20 min intervals, 20 replicates) at 6 dilution rates of the polluted soil. Differences between control and polluted side tested by sign test (N.S. $=$ not significant; ${ }^{*},{ }^{* *},{ }^{* \star}=$ significant at $0.05,0.01$ and 0.001 level, respectively). Control value is $50 \%$ 


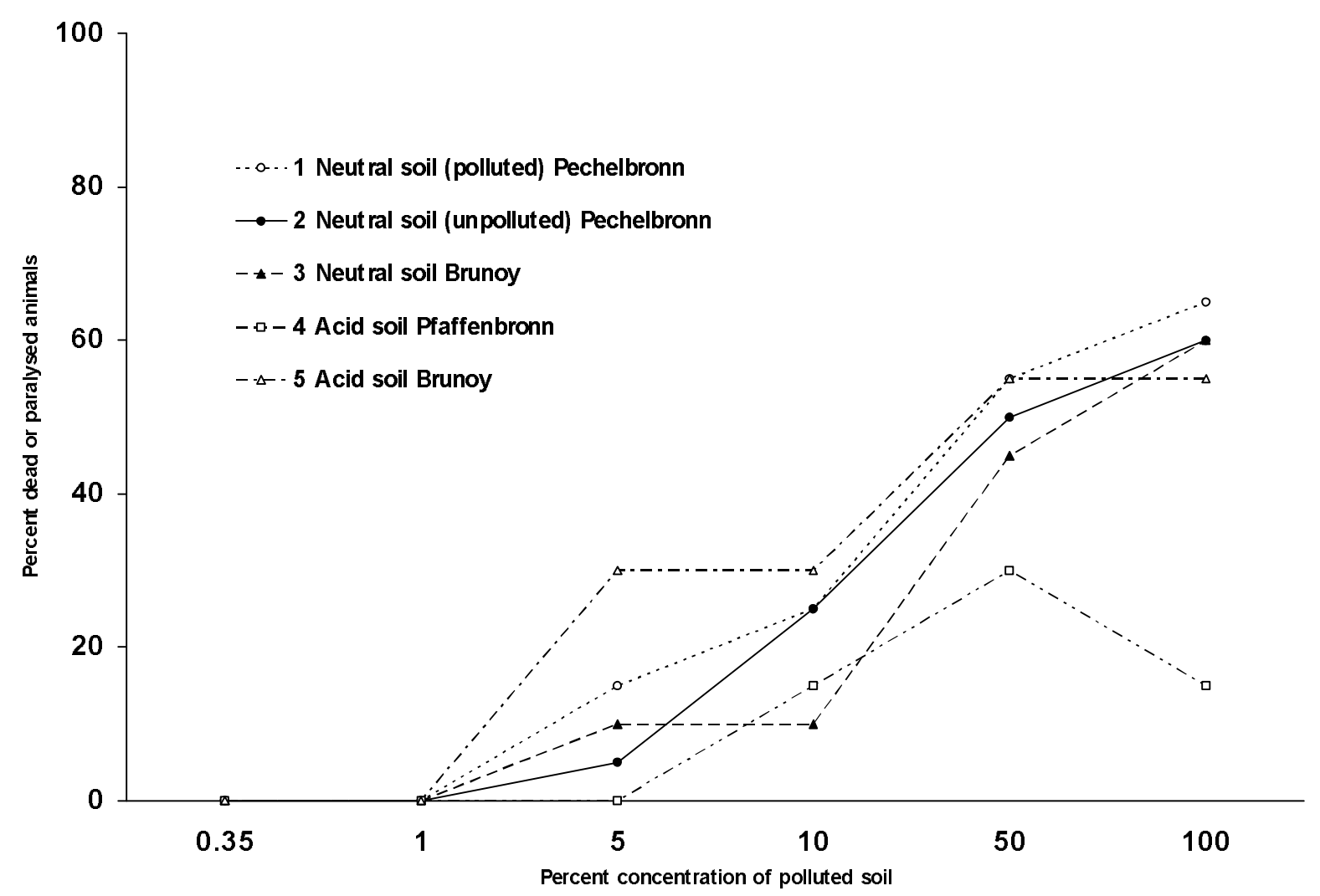

Fig. 2. Avoidance tests. Percent dead or paralysed specimens of five strains of Folsomia candida during the experimental run (100 min.). Control value is 0 


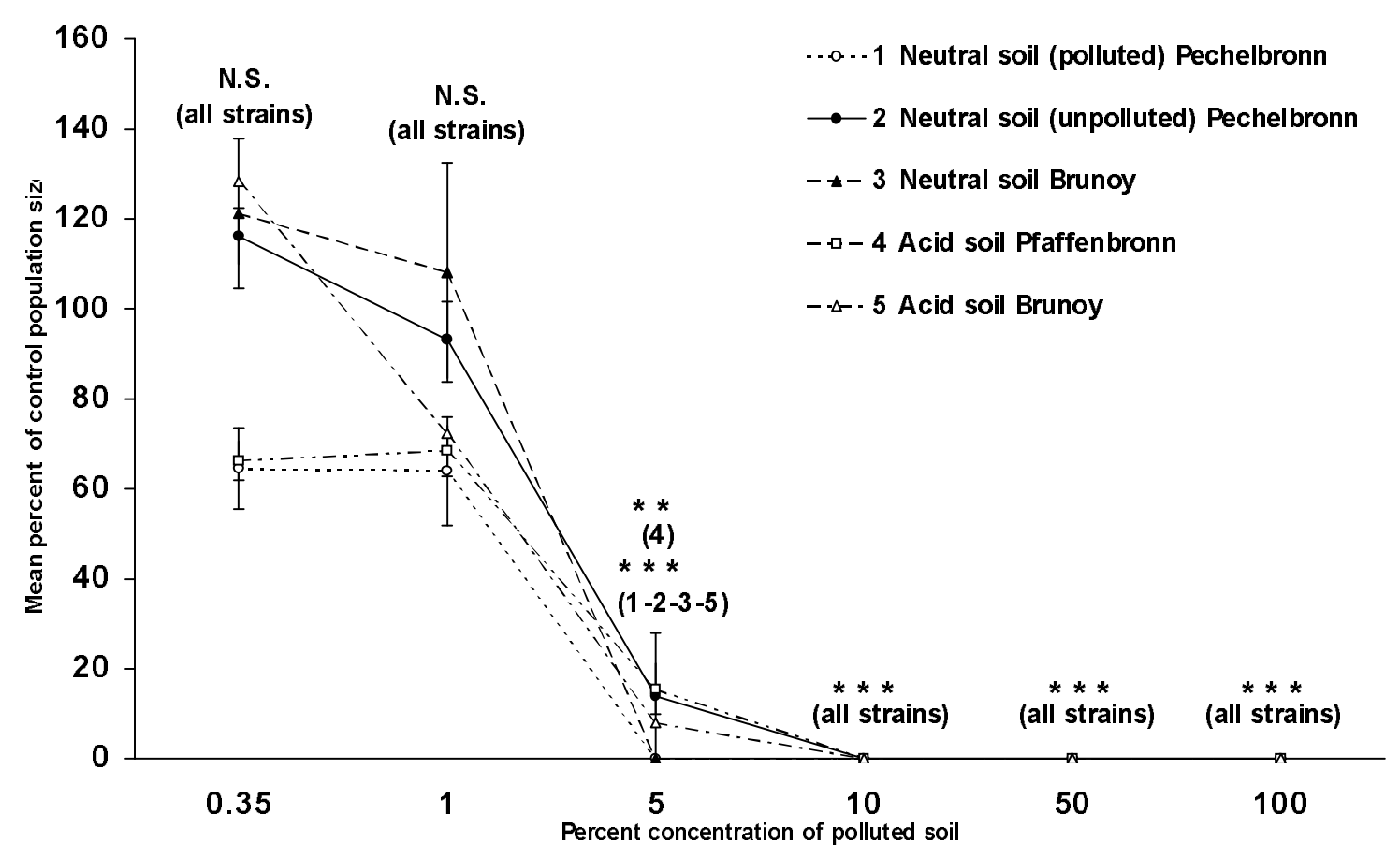

2 Fig. 3. Population tests. Population size (mean of 5 replicates \pm standard error) of five strains of Folsomia candida after 40 days in contact with 6 dilution rates of the polluted soil, expressed as percent of the control value (all counts were divided by the mean number of animals in the 5 control microcosms). Ten adult individuals per microcosm. Differences with the control were tested by t-test (N.S. = not significant at 0.05 level, ${ }^{\star *}=$ significant at 0.01 level, ${ }^{* \star}=$ significant at 0.001 level) 